\title{
Consumer Purchase Motives And Product Perceptions: A "Hard" Laddering Study Of Smoking Habits Of Poles
}

Eugene Kaciak, (E-mail: ekaciak@brocku.ca), Brock University, Canada Carman W. Cullen, (E-mail: cwcullen@brocku.ca), Brock University, Canada

\begin{abstract}
The objective of the study is to apply the Means-End Theory to the analysis of smoking habits of Poles, based on a quota sample of 418 smokers in Krakow. The Means-End Theory posits that consumers learn to associate attributes (A) of products with particular consequences $(C)$, and that these consequences are important because they accord with personal values (V) held by the individual. Each chain of associations $A-->C-->V$ depicts the consumer's personal motivations with respect to a given product. The "paper-and-pencil assisted" approach (which is called "hard" laddering, as opposed to "soft", conventional tape-recorded interviews) is used to uncover links between personal values and the smokers' choices. The results are then transposed into a meaningful market segmentation strategy.
\end{abstract}

\section{INTRODUCTION}

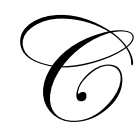

igarette smoking and other tobacco use imposes a huge and growing public health burden virtually in every country in the world. Currently, approximately 4 million people are killed annually by tobacco use (Chaloupka et al., 2001). Governments have tried different tactics with the aim to control the marketing of cigarettes and to constrain smoking, such as enacting laws restricting or outright banning of cigarette advertising, higher taxes on tobacco products, restrictions on smoking in public places, prominent health warning labels, massmedia counter advertising, etc. In most cases, however, the results were not impressive. Smoking declined somewhat, but the restrictions certainly did not achieve the anticipated goal of eliminating smoking (Hamilton, 1972; Stewart, 1993; Beck, 1997; The World Bank Report, 1999).

Critics of government social activism say such results demonstrate that governments often have little clout when they attempt to re-engineer human behavior (High, 2000). There is a growing conviction among researchers that using only administrative measures may not be enough because of a number of reasons. Cigarette advertising bans usually eliminate at the same time health warnings - they can be seen only on the cigarette packs, mostly by those who already smoke. Cigarette advertising bans create a false confidence that "we have done everything". There is too much emphasis on the advertising and fighting it, whereas the tobacco companies use much more subtle and therefore dangerous ways of popularizing smoking among newcomers, such as brand stretching, heavy advertising and promotions of "light" brands, promotional campaigns, sponsorship of sporting and cultural events, funding of scientists and research institutions, funding of political parties and their representatives/legislators, product placements in films, point of sale tobacco advertising, direct marketing, or internet (e.g. Pierce et al., 1998; Jarvis, 1998). An effective anti-smoking program must be built on the solid foundation of consumer behavior research (Wyckham, 1997). Surprisingly, there are not many studies that concentrate on answering the behavioral question why people smoke. The existing studies focus mainly on the impact of the above mentioned administrative measures on the tobacco consumption (Stewart, 1993; The World Bank Report, 1999; Pechmann and Knight, 2002).

The objective of our study is to help those responsible for public health gain knowledge and understanding why adults continue to consume tobacco products. This might help them to design tactics that would counter the 
sophisticated practices of the tobacco manufacturers. The study was conducted in Poland, where one in three adults is a smoker (USDA Gain Report, 2000), however it is hoped that its findings could apply to other countries as well.

To achieve our research objective, we collected and analyzed the data with a laddering method, founded in the Means-End Theory.

\section{THE MEANS-END THEORY}

The Means-End Theory is one among several theories that have developed in cognitive psychology in order to understand how consumers perceive self-relevance consequences of products (Gutman, 1982). It is built on the work of psychologists (e.g. Tolman, 1932; Rosenberg, 1956) and economists (e.g. Abbott, 1955) who claimed that products are purchased and consumed not for their own sake, but because they mean something to the consumer (Reynolds and Gutman, 1988).

The Means-End Theory (Gutman, 1982) posits that consumers learn to associate attributes (A) of products with particular consequences $(\mathrm{C})$, and that these consequences are important because they accord with personal values (V) held by the individual. Since the theory suggests that people choose products leading to consequences in keeping with their personal values, each sequence of associations A-C-V among a specified attribute, consequence and value will depict the consumer's personal motivations with respect to a given product. Uncovering a link between personal values and smokers' choices may prove useful for answering the question why people smoke.

The choice of cigarettes appears to be well suited to a means-end experiment (Aurifeille and ValetteFlorence, 1992a,b and 1995). Cigarette consumption involves important individual and social consequences (Moschis, 1989). Strong relations between smoking and the smoker's self-concept have been observed by researchers (Chassin et al., 1981; Sheth et al., 1991). Smoking has often been associated with strong brand preferences (Chapman and Fitzgerald, 1982) and behavioral consequences (Grube et al., 1984). Moreover, most smokers do think about the consequences of smoking and thus their cognitive structures are already well articulated. This limits the risk of artificially prodding them in the course of the data gathering exercise (Grunert and Grunert, 1995).

The number of studies using Means-End Theory in the analysis of smoking behavior is surprisingly small (Mount and Kaciak, 1993; Aurifeille and Valette-Florence, 1992a,b and 1995); we note that cigarette smoking is also investigated by Grube et al. (1984), however, not from the Means-End Theory perspective. One possible explanation is that the conventional face-to-face tape-recorded laddering interviews (the so called "soft" laddering; Grunert and Grunert, 1995) are time consuming, costly, do not offer any anonymity, and are usually limited to small sample sizes that do not yield meaningful results. In our approach we will explore another data collection possibility, different from the conventional tape-recorded, interview-based, "soft" laddering approach. We will use a free elicitation print instrument that is formulated according to a carefully defined pattern:

1. Each consumer individually writes the most important (according to his/her judgment) attribute (A) of the product in question (in this case: cigarettes).

There are a number of methodologies helping the respondent to identify product attributes, for example triadic sorting, free sorting, ranking, selection from a predetermined attribute list, or direct elicitation. The comparative studies of these methodologies (Bech-Larsen, et al., 1997; Bech-Larsen and Nielsen, 1999) suggest that more complicated methods like triadic sorting do not seem to outperform simpler methods like direct elicitation. In our study we use the direct elicitation method (also used, for example, by Miles and Frewer, 2001), which also seems to be the most appropriate in cases when the respondent is left alone with the laddering questionnaire to fill out.

2. Then, he/she writes up to three perceived consequences (C) resulting from this attribute.

Since we were studying cigarette smoking, we decided to replace the term "consequences" with the term "benefits" (the same approach was used by Mount and Kaciak, 1993). We came to the conclusion that asking for the consequences of smoking would trigger only well known, obvious, and therefore trivial, answers such as "smoking is bad for health", or "smoking is a waste of money", etc. We wanted to discover in our study the reasons why people 
smoke and therefore asked for "benefits" of smoking. This approach worked very well - only three respondents gave us their comments about the use of the term "benefits" (their comments are presented in the next section). The specific use of the term "benefits" instead of "consequences" in a laddering research can be also found in Gutman's (1997) beverage study and the yogurt study of Hofstede et al. (1999).

3. Finally, he/she provides up to three reasons why each of these consequences (in our case - benefits) is important to him/her, which later will (hopefully) be translated by the researchers into one of the widely accepted sets of values (V), for example the Rokeach Value Survey - RVS (Rokeach, 1973), the List of Values - LOV (Kahle, 1983), or the Schwartz Value Domains (Schwartz, 1992, 1994).

Thus, it is theoretically possible for one respondent to generate, for one attribute, nine A-C-V ladders, each ladder starting at the attribute, passing through one of the three consequences, and ending with one of the nine possible values. In our questionnaire, we encourage each respondent to repeat the above procedure three times, each time for a different attribute.

The above-described pattern was - to the best of our knowledge - first designed and applied by Mount and Kaciak (1993). On their questionnaire, each of three attributes was followed by three sequences of boxes connected by arrows, and subjects had to fill in the boxes. Each sequence of boxes included one box where a respondent would write the attribute-associated consequence, and three boxes where he/she would provide reasons why this consequence was important. There is some similarity between this approach and the "Great Benefit Chain" formula, developed by Young and Feigin (1975). These researchers also advocate using a self-administered probing device, however only in order to elicit "product-related and emotional benefits" from the product's attribute. The difference between the two approaches is that Young and Feigin (1975) focus only on the product attributes (A) and the associated benefits (i.e. $\mathrm{C}$ ), and do not pursue the questioning in order to discover the ultimate values (V) that govern the consumer choices. This is probably because at this time the list of human values (Rokeach, 1973) was just in its early years of acceptance. Another laddering questionnaire was used by Walker and Olson (1991), in a study exploring means-end relationships for sending greeting cards. Walker and Olson (1991) do not report the exact format of their questionnaire. It seems, however, that they focused mainly on the connections between the product attributes and the underlying end-values, and ignored the intermediate level of the A-C-V chains, i.e. the attribute-associated consequences (C). In summary, Young and Feigin (1975) developed the A-C chains, whereas Walker and Olson (1991) generated the A-V structures. Mount and Kaciak (1993) put these two approaches together and chained all three A-C-V questions in a self-administered questionnaire. In this study we follow their approach hoping to derive information of the same scope (breadth of attributes addressed and depth within the chain) as the "soft" laddering interview furnishes. Such an instrument may be administered in less time and at a lower cost to a much larger sample, thereby permitting the researcher to reach conclusions that are more meaningful.

Other examples of studies that use the "paper-and-pencil" approach include: Pieters et al. (1994) - they applied the paper-and-pencil method in the empirical study of the word-processing software; Pieters et al. (1995) they used sequences of boxes connected by arrows that respondents had to fill in with the aim of discovering reasons for wanting to lose weight; Gutman (1997) - he used a self-administered laddering questionnaire that guided the respondent from the product attribute to associated benefits and underlying reasons (goals). His approach seems to be the closest to the questionnaire advocated by Mount and Kaciak (1993); Botschen and Hemetsberger (1998); Botchen and Thelen (1998) - they used sequences of boxes connected by arrows taking the respondent from each product attribute to reasons explaining why this attribute was important to them; Pieters et al. (1998) - they used sequences of four boxes connected by arrows that respondents had to fill in with the aim of eliciting customer desire expectations about service-employees; Miele (2000) - she used a "hard" laddering, questionnaire-based, approach to investigate consumers attitudes towards animal welfare; Valette-Florence et al. (2000) - they used a "hard" laddering method to analyze fish consumption in Denmark and France.

The above described "paper-and-pencil assisted", questionnaire-based approaches belong to the family of "hard" laddering methods (Grunert and Grunert, 1995) which also includes "hard"-laddering-based-interviews (Jonas and Beckmann; 1998), computer-assisted questionnaires (Reynolds et al., 1995); Russel et al., 2003), telephoneassisted questionnaires (Bagozzi and Dabholkar, 1994 and 2000), and the so called association pattern technique APT (Hofstede et al., 1998; Feunekes and den Hoed, 2001, Russel et al., 2003). 


\section{POPULATION, SAMPLE, AND DATA COLLECTION}

The study was conducted in summer 1998 in Krakow, Poland, a city of 750,000. The subjects of the study were inhabitants of Krakow who smoked cigarettes and agreed to participate in our project.

Our aim was to use a quota sample of at least 400 smokers, so that the results of the study could be analyzed in a meaningful way. To achieve this objective, we trained 110 undergraduate marketing students of the Krakow Academy of Economics. First, the students were exposed to the means-end theory and laddering methods during several marketing research classes. Then, each of them filled out our laddering questionnaire and provided the researchers with comments about this exercise. Since most of the students were not smokers, the topic of this pilot study was wine consumption. As a result of this feedback, we modified the smoking questionnaire by adding in the upper right corner of the first page a short example listing possible wine attributes, associated consequences, and reasons for drinking wine. As possible attributes of wine (following the advice of our students, we eventually used the term "characteristics", as easier to understand) we offered: crispy, sweet, expensive, and low alcohol content). As an example of a benefit stemming from the attribute "Low alcohol content" we pointed to "Avoid getting drunk". Finally, we offered "Maintain respect of others" as a possible reason why "Avoid getting drunk" could be important to the respondent. We adopted the above example of a wine ladder from the laddering study described in Reynolds and Gutman (1988). We admit that adding this example of a wine ladder was a subject of lengthy discussions among the researchers. We did not want the smokers filling out the questionnaire to be in any way influenced by our choice of these exemplary terms. That is why we were careful not to offer too many ideas that might apply also to smoking.

Each of the 110 students was responsible for administering the laddering questionnaire to four smokers of his/her choice, under the condition that they would match the predetermined socio-demographic characteristics according to the requirements of the quota-sample. The students were supposed to return the filled out questionnaires in two weeks. We did not control the way the questionnaires were being filled out. At the end of the survey period we did however interview a number of students about the approach they took to administering the questionnaires. It turned out that some students assisted the respondents in answering the questions (e.g. guided them through the questions, explained the purpose of the study and the meaning of the terms used), while others left empty questionnaires with the respondents and picked up the filled out questionnaires later. The former approach could be termed "hard laddering with assistance", similar to the approach used by Miele (2000), who administered the laddering questionnaires during half an hour interviews, or - to some extent - to the card-sorting task used by ValetteFlorence (1998). The latter one represents "hard laddering without assistance". This duality of approaches is admittedly a limitation of our study.

We were aiming at receiving 440 filled out questionnaires and at the end received 436 (one student resigned from the study due to health problems).

Out of 436 returned questionnaires, 13 were outright rejected since they were either empty or almost empty. Subsequent analysis revealed two instances when two questionnaires have been answered in almost identical way. This suggested some kind of tampering with the data and therefore we rejected all 4 questionnaires.

Three respondents decided to share their comments about the study. The first respondent stopped filling out the questionnaire after having provided only one attribute (STRONG cigarettes) with two subsequent ladders. He commented that he could not continue any further because it was expected from him to speak positively about the product that he knows is undoubtedly harmful. He smokes only because he is addicted to the nicotine and can not provide any other benefits of smoking. The second respondent complained that the questionnaire was not clear enough. Nevertheless, he managed to provide several meaningful ladders. The third respondent commented (after having provided several ladders) that actually smoking has no benefits what so ever, and therefore his answers, describing how good it is to smoke, should not be treated seriously. We therefore did not retain this questionnaire for further analysis. 
Table 1: Socio-demographic structure of the sample and the population (1998)

\begin{tabular}{|c|c|c|c|c|c|}
\hline & & Sample & Percent & Krakow & Percent \\
\hline & & $(n=418)$ & (Sample) & Population & (Krakow) \\
\hline \multirow[t]{2}{*}{ Gender: } & MALE & 218 & $52.20 \%$ & 347,596 & $46.90 \%$ \\
\hline & FEMALE & 200 & $47.80 \%$ & 393,070 & $53.10 \%$ \\
\hline TOTAL $=$ & & 418 & & 740,666 & \\
\hline \multirow[t]{3}{*}{ Marital Status: } & SINGLE & 118 & $28.20 \%$ & No data & \\
\hline & MARRIED & 259 & $62.00 \%$ & & \\
\hline & W/S/D* & 41 & $9.80 \%$ & & \\
\hline TOTAL $=$ & & 418 & & & \\
\hline \multirow[t]{4}{*}{ Finished Education: } & PRIMARY SCHOOL & 33 & $7.90 \%$ & No data & \\
\hline & VOCATIONAL SCHOOL & 70 & $16.70 \%$ & & \\
\hline & HIGH SCHOOL & 128 & $30.60 \%$ & & \\
\hline & COLLEGE & 15 & $3.60 \%$ & & \\
\hline \multirow[t]{2}{*}{ (Currently) } & UNIVERSITY STUDENT & 51 & $12.20 \%$ & 112,638 & $15.20 \%$ \\
\hline & UNIVERSITY & 121 & $28.90 \%$ & & \\
\hline TOTAL $=$ & & 418 & & & \\
\hline \multirow[t]{11}{*}{ Age: } & [18-22) Years & 48 & $11.50 \%$ & 61,563 & $10.50 \%$ \\
\hline & {$[22-27)$} & 87 & $20.90 \%$ & 61,941 & $10.50 \%$ \\
\hline & {$[27-32)$} & 52 & $12.50 \%$ & 47,825 & $8.10 \%$ \\
\hline & {$[32-37)$} & 46 & $11.10 \%$ & 47,134 & $8.00 \%$ \\
\hline & {$[37-42)$} & 30 & $7.20 \%$ & 56,393 & $9.60 \%$ \\
\hline & {$[42-47)$} & 44 & $10.60 \%$ & 62,208 & $10.60 \%$ \\
\hline & {$[47-52)$} & 38 & $9.10 \%$ & 55,777 & $9.50 \%$ \\
\hline & {$[52-57)$} & 34 & $8.20 \%$ & 43,188 & $7.30 \%$ \\
\hline & [57-62) & 18 & $4.30 \%$ & 36,730 & $6.20 \%$ \\
\hline & {$[62-67)$} & 6 & $1.40 \%$ & 36,779 & $6.20 \%$ \\
\hline & [67 OR MORE & 13 & $3.10 \%$ & 79,109 & $13.50 \%$ \\
\hline TOTAL $* *=$ & & 416 & & 588,647 & \\
\hline \multirow[t]{6}{*}{ Household Size: } & 1 PERSON & 61 & $14.60 \%$ & No data & \\
\hline & 2 PERSONS & 62 & $14.90 \%$ & & \\
\hline & 3 PERSONS & 129 & $30.90 \%$ & & \\
\hline & 4 PERSONS & 109 & $26.10 \%$ & & \\
\hline & 5 PERSONS & 48 & $11.50 \%$ & & \\
\hline & $6+$ PERSONS & 8 & $1.90 \%$ & & \\
\hline TOTAL $* *=$ & & 417 & & & \\
\hline \multirow[t]{7}{*}{ Income $* * *$} & LESS THAN 300: Very low & 4 & $1.00 \%$ & No data & \\
\hline & {$[300-700):$ Low } & 40 & $9.60 \%$ & & \\
\hline & [700 - 1,100): Lower middle & 78 & $18.80 \%$ & & \\
\hline & {$[1,100-1,500):$ Middle } & 149 & $35.80 \%$ & & \\
\hline & {$[1,500$ - 2,500): Upper middle } & 92 & $22.10 \%$ & & \\
\hline & {$[2,500-4,500):$ High } & 37 & $8.90 \%$ & & \\
\hline & [4,500 OR MORE: Very high & 16 & $3.80 \%$ & & \\
\hline TOTAL $* *=$ & & 416 & & & \\
\hline
\end{tabular}

* W/S/D = Widowed/Separated/Divorced; **) Some data in the sample were missing;

***) Per capita monthly gross income (in PLN; 1 USD = 4.5 PLN)

Note 1: Average monthly gross salary in Krakow in 1998 was 1,354 PLN.

Note 2: In 1998, $40 \%$ of men and $20 \%$ of women in Poland were smokers.

Each student received a card with four socio-demographic profiles of the desired respondents, e.g.

(1) Female/Age [32-37)/Education (Vocational School), (2) Male/Age [22-27)/Education (High School), (3) Female/Age 77+/Education (Primary School), (4) Male/Age [27-32)/Education (High School). 
In summary, we rejected, due to the above reasons, 18 questionnaires, which brought the final number of usable questionnaires down to 418 . Table 1 describes socio-demographic characteristics of the respondents. We had complete information on gender and age proportions in Krakow, and limited data on the education variable. Therefore, we aimed at controlling two variables in the quota sample - gender and age - so that their proportions in the sample match the corresponding proportions in the city. We also attempted to control the third variable, education, through the application of the following two principles:

- $\quad$ The proportion of students in the sample should match the proportion of students in Krakow;

- The rest of the sample should be evenly distributed among three major education levels: primary/vocational, high school, and college/university.

Students were given an opportunity to pick a card with the profiles that best suited their ability to find the appropriate respondents. This was done on a first-come-first-served basis, and in general went quite smoothly.

\section{CONTENT ANALYSIS}

\section{Recording the answers and preliminary coding}

We recorded each questionnaire in a spreadsheet table, adapting the method used by Valette-Florence and Rapacchi (1991). We allocated each respondent to a separate column, and the answers they provided to three row sections. The first section of rows was reserved for the answers that the respondents provided to the attribute-related questions. The second section was reserved for the answers through which the respondents described the benefits of smoking resulting from a given attribute, and the third one - for the answers explaining reasons why each of these benefits was important to them. According to the Means-End theory we consider these reasons to be possible values underlying the respondents' choices. We used the standard 0-1 coding, where 1 at the intersection of the i-th row and the $\mathrm{j}$-th column indicated that the $\mathrm{j}$-th respondent gave the $\mathrm{i}$-th answer to a given question.

In total, 5,103 answers (excluding answers to the socio-demographic questions) were provided by the 418 respondents, ranging from 1 to 32 answers per person (the theoretical maximum was $39=3 \times 1+3 \times 3+3 \times 9$ ), with an average of 12.2 answers per person. Obviously, many respondents gave identical or very similar answers. For popular answers (e.g. STRONG, or HIGH NICOTINE LEVEL), we created only one common idiosyncratic concept (STRONG) for all respondents who pointed to this attribute of cigarettes. Thus all these respondents would be assigned code 1 in the row with the Attribute $=$ STRONG. In cases when assigning an answer to a previously created concept was not absolutely obvious, we recorded such an answer as a new concept, exactly as it was provided by the respondent - without any attempt to code it at this stage. This approach allowed us to minimize the number of subjective decisions made by the coders during the preliminary coding process.

The number of different idiosyncratic concepts that we first found among the 5,113 answers was 2,045, i.e. 4.9 concepts, on average, per person. Other studies have elicited the following numbers of concepts: Makatouni (2002) reported 402 "concepts" resulting from 40 laddering interviews about reasons to buy organic food (an average of 10 concepts per respondent); Bagozzi and Dabholkar (1994), in a study of consumer decisions to recycle, received 981 "goals" from 133 respondents (an average of 7.3 goals per respondent, ranging from 2 to 15); Pieters et al. (1995) found 342 "goals" mentioned by 51 subjects in a study of weight loss (an average of 6.7 goals per subject); Bagozzi and Dabholkar (2000) elicited 2,390 "cognitions" from 450 laddering interviews over the phone (an average of 5.3 cognitions per respondent, ranging from 2 to 17) in a study of public's perception of President Clinton.

Our study has the lowest average number of concepts per person, among all the above studies. This could be attributed to at least two reasons. First, the topic of our study is less general than the topics of these studies. Second, the smokers' level of experience with cigarettes is probably the highest among the experience levels that other respondents have with the topics listed above. As a result, the answers that we obtained in our smoking study may have been more precise and hence easier to code than those in other, more general, studies. 
A subsequent examination by the researchers of the list of the initial 2,045 concepts revealed that they could further be compressed into 1,366 concepts-categories without losing any significant information. Among the 1,366 categories, there were 46 attribute categories, 1,036 benefit categories, and 284 value related categories.

The entries of the resulting 1,366x418 indicator matrix are either 0 or 1 . Because the number of columns that could fit into our spreadsheet is limited to 256 , we had to partition this matrix into two sub-matrices. The two submatrices were combined together after the number of categories has later been reduced through the coding process.

\section{Coding of the attribute categories}

Two external judges were independently given a task of content analyzing and collapsing the initial 46 attribute categories into a lower number of categories without losing any significant information. They were quite unanimous in their choice of the 17 attribute categories, listed in Table 2. The inter-judge reliability measured with Cronbach's alpha was $87 \%$. All disagreements between the two judges were resolved jointly during meetings with the researchers so that all attribute categories were eventually coded. During the final brainstorming session the two judges and researchers further agreed that these 17 attributes could be classified into 6 more general categories, as shown in Table 2.

Table 2: Attribute codes

\begin{tabular}{|l|c|c|}
\hline ATTRIBUTE CATEGORIES & CODES & FINAL CODING \\
\hline 1. Mild (Low Tar/Nicotine) & $\mathrm{A} 1$ & MILD \\
\hline 2.Taste & $\mathrm{A} 2$ & TASTE/AROMA \\
\hline 3. Aroma & $\mathrm{A} 2$ & TASTE/AROMA \\
\hline 4. Menthol & $\mathrm{A} 2$ & TASTE/AROMA \\
\hline 5. Expensive & $\mathrm{A} 3$ & GOOD QUALITY \\
\hline 6. Long and Slim & $\mathrm{A} 3$ & GOOD QUALITY \\
\hline 7. Elegant package & $\mathrm{A} 3$ & GOOD QUALITY \\
\hline 8. Foreign made & $\mathrm{A} 3$ & GOOD QUALITY \\
\hline 9. Good brand name & $\mathrm{A} 3$ & GOOD QUALITY \\
\hline 10. Good quality & $\mathrm{A} 3$ & GOOD QUALITY \\
\hline 11. Cheap & $\mathrm{A} 4$ & CHEAP \\
\hline 12. Domestic made & $\mathrm{A} 4$ & CHEAP \\
\hline 13. Without filter & $\mathrm{A} 5$ & STRONG \\
\hline 14. Strong & $\mathrm{A} 5$ & STRONG \\
\hline 15. Short* & $\mathrm{A} 5$ & STRONG \\
\hline 16. Non-aromatized & $\mathrm{A} 5$ & STRONG \\
\hline 17. With filter & $\mathrm{A} 6$ & WITH FILTER \\
\hline
\end{tabular}

* In order to classify this particular attribute we had to check again the questionnaires. We found out that respondents who gave this characteristic wanted to smoke in their work but did not have too much time for it. Therefore, they wanted a shorter cigarette which would allow them to finish it faster, but in return they wanted it also stronger in order to satisfy their nicotine hunger.

There were 9 attribute categories obtained in another study on smoking (Aurifeille and Valette-Florence, 1992): six concrete attributes (Low nicotine, Strength, Low tar, Moderate price, Packaging, and Length), and three abstract attributes (Taste, Odour, and Flavor). The attributes elicited in our study match surprisingly well the above attributes, despite the fact that the samples come from two different countries, Poland and France. The numbers of attributes obtained in other, non-smoking related, studies, vary from 8 (Hofstede et. al., 1999) to 31 (Gutman, 1984), and 34 (Kohler and Junker, 2000), with an average number of attributes equal 16. 


\section{Coding of the benefit categories}

The same two judges were given another task of content analyzing and further compressing the initial 1,036 benefit categories. They found this to be a very challenging exercise, which resulted in a very low (68\%) inter-judge level of agreement. During subsequent meetings, the judges and researchers re-checked a number of questionnaires in order to solve all the controversies. This task was possible thanks to the fact that each of the benefit categories (as well as the attribute and value categories) was tagged with the number of the respondent who provided it. At the end of this time consuming procedure, the 1,036 benefit categories were collapsed into 39 classes (Table 3 ).

Again, during the final brainstorming session, the two judges and researchers agreed that these 39 benefits could be further classified into 6 more general categories, as presented in Table 3.

Table 3: Benefit codes

\begin{tabular}{|c|c|c|}
\hline \\
\hline BENEFIT CATEGORIES & CODES & FINAL CODING \\
\hline 1. Forget about monotony/Way to fight boredom & B1 & PLEASURE \\
\hline 2. Pleasure & $\mathrm{B} 1$ & PLEASURE \\
\hline 3. Satisfaction & $\mathrm{B} 1$ & PLEASURE \\
\hline 4. I feel that I smoke & B1 & PLEASURE \\
\hline 5. I feel taste & B1 & PLEASURE \\
\hline 6. Comfortable smoking & B1 & PLEASURE \\
\hline 7. I smoke more cigarettes & B1 & PLEASURE \\
\hline 8. Excitement/New experiences & B1 & PLEASURE \\
\hline 9. Longer smoking time & B1 & PLEASURE \\
\hline 10. Pleasure from smoking strong cigarettes & B1 & PLEASURE \\
\hline 11. Pleasure from smoking light cigarettes & B1 & PLEASURE \\
\hline 12. Relaxation/Calmness & $\mathrm{B} 2$ & FEEL PHYSICALLY BETTER \\
\hline 13. Feel better (physically) & $\mathrm{B} 2$ & FEEL PHYSICALLY BETTER \\
\hline 14. Better concentration/Clear mind & $\mathrm{B} 2$ & FEEL PHYSICALLY BETTER \\
\hline 15. Satisfy nicotine hunger & $\mathrm{B} 2$ & FEEL PHYSICALLY BETTER \\
\hline 16. Positive impact on health & $\mathrm{B} 2$ & FEEL PHYSICALLY BETTER \\
\hline 17. Minimize unpleasant consequences of smoking & B3 & LESS DAMAGE TO HEALTH \\
\hline 18. Less damaging/Less poisonous & B3 & LESS DAMAGE TO HEALTH \\
\hline 19. Better quality cigarettes & B3 & LESS DAMAGE TO HEALTH \\
\hline 20. I smoke fewer cigarettes & B3 & LESS DAMAGE TO HEALTH \\
\hline 21. Less nicotine/tar & B3 & LESS DAMAGE TO HEALTH \\
\hline 22. Less damage to my family's health & B3 & LESS DAMAGE TO HEALTH \\
\hline 23. Less damage to the health of others & B3 & LESS DAMAGE TO HEALTH \\
\hline 24. Know what to do with my hands/Feel sure of myself & B4 & I PROJECT GOOD IMAGE \\
\hline 25. Clean teeth/hands/hair/breath & B4 & I PROJECT GOOD IMAGE \\
\hline 26. Eat less/Better weight control & B4 & I PROJECT GOOD IMAGE \\
\hline 27. Strength/Masculinity & B4 & I PROJECT GOOD IMAGE \\
\hline 28. Better looking cigarettes & B4 & I PROJECT GOOD IMAGE \\
\hline 29. Want to look good/Feel attractive & B4 & I PROJECT GOOD IMAGE \\
\hline 30. Feel elegant & B4 & I PROJECT GOOD IMAGE \\
\hline 31. One does not feel smoke that much & B5 & IS SOCIALLY ACCEPTABLE \\
\hline 32. No guilty feelings/Clean conscious & B5 & IS SOCIALLY ACCEPTABLE \\
\hline 33. Can smoke at work & B5 & IS SOCIALLY ACCEPTABLE \\
\hline 34. Easy to buy & B6 & I SAVE MONEY/TIME \\
\hline 35. More money for other things & B6 & I SAVE MONEY/TIME \\
\hline 36. Save time & B6 & I SAVE MONEY/TIME \\
\hline 37. Save money & B6 & I SAVE MONEY/TIME \\
\hline 38. I can buy more cigarettes & B6 & I SAVE MONEY/TIME \\
\hline 39. Can make ends meet & B6 & I SAVE MONEY/TIME \\
\hline
\end{tabular}


Aurifeille and Valette-Florence (1992) elicited 11 consequence categories in their study on smoking: four functional consequences (Physical Attributes: fingers, teeth, etc; Relaxation: health; Hunger suppressant; and Physical satisfaction), and seven psychosocial consequences (Reserve: avoid conflicts; Prestige/charm; Self-confidence; Identity: differentiation; Communication; Kills time; and Enhanced concentration). Again, the benefits elicited in our study match amazingly well the above categories. The numbers of consequences obtained in other, non-smoking related, studies, vary from 7 (Klenosky et al., 1993) to 37 (Russel et. al., 2004), and 42 (Kohler and Junker, 2000), with the average number 21.9

\section{Coding of the value categories}

Each judge was provided with the list of 56 values, established by Schwartz (1994) in a study of 97 samples in 44 countries. There are, of course, other widely accepted lists of values, such as the Rokeach Value Survey - RVS (Rokeach, 1973), or the List of Values - LOV (Kahle, 1983). We made a conscious choice of using the Schwartz's values because his study is based on international, cross-cultural data, and as such seems to be the best for comparing the results of laddering studies from different countries. Schwartz's classification has been employed in studies of values conducted in Europe, e.g. Schwartz and Bilsky (1990), Grunert and Juhl (1991), Coolen and Hoekstra (2001). Using the above list of 56 values, each judge coded the 284 value categories that have been elicited in our study. The inter-judge reliability was found to be $69 \%$. Based on this initial coding, the researchers and the judges agreed, after lengthy deliberations, that the 284 value categories could be classified into 12 out of the 56 Schwartz's values (Table 4). These values represent 7 out of 10 of Schwartz's value domains (Schwartz, 1994).

Table 4: Schwartz value domains and values

\begin{tabular}{|l|l|}
\hline \multicolumn{1}{|c|}{ VALUE DOMAINS } & RETAINED VALUES \\
\hline I. POWER & 1. Preserving my public image \\
\hline & 2. Social recognition \\
\hline II. ACHIEVEMENT & 3. Capable \\
\hline III. HEDONISM & 4. Pleasure \\
\hline & 5. Enjoying life \\
\hline IV. STIMULATION & \\
\hline V. SELF-DIRECTION & 6. Freedom \\
\hline & 7. Choosing own goals \\
\hline & 8. Independent \\
\hline VI. UNIVERSALISM & \\
\hline VII. BENEVOLENCE & 9. Responsible \\
\hline VIII. TRADITION & \\
\hline IX. CONFORMITY & 10. Politeness \\
\hline & 11. Obedient \\
\hline X. SECURITY & 12. Healthy \\
\hline
\end{tabular}

\section{STRUCTURAL ANALYSIS}

\section{Summary implication matrix}

The first step of our structural analysis was to create a summary implication matrix (Table 5). In this matrix, one can observe both direct and indirect links in each pair of categories. For example, there are 45 ladders depicting a direct connection between the attribute A1 and the benefit B1, 317 ladders showing a direct link between the benefit $\mathrm{B} 1$ and the value V3, 58 ladders indicating an indirect link between the attribute A5 and the value V2, etc.

The summary implication matrix shows 17 direct links between the attribute and benefit categories, 19 direct links between the benefit and value categories, and 29 indirect links between the attribute and value categories. Thus, the total number of direct and indirect links is 65 . The total number of ladders is 1,347 , with an average of 3.2 ladders 
per respondent. The average number of ladders per person reported in other studies varies between 2.82 (Mount and Kaciak, 1993) and 6.03 (Deeter-Schmeltz et. al., 2002), and 7.6 (Sorensen et al., 1996).

Our summary implication matrix could also be represented as a square19x19 $(19=6$ attributes, 6 benefits, and 7 values) matrix, which is the most frequently chosen format in the laddering literature. The sizes of the summary implication matrices reported in other studies vary from 12x12 (Pieters et al., 1995) to 69x69 (Bagozzi and Dabholkar, 2000) or even 87x87 (Makatouni, 2002). The most typical size is around 30x30 (e.g. Deeter-Schmeltz et. al., 2001; Coolen and Hoekstra, 2001; Botschen and Hemetsberger, 1998).

Table 5: Summary implication matrix (SIM)

\begin{tabular}{|c|c|c|c|c|c|c|c|c|c|c|c|c|c|c|c|c|}
\hline & B1 & B2 & B3 & B4 & B5 & B6 & Total & & V1 & V2 & V3 & V4 & V5 & V6 & V7 & Total \\
\hline A1 & 45 & & 222 & 15 & 38 & & 320 & A1 & 144 & 54 & 34 & 10 & 13 & 65 & & 320 \\
\hline A2 & 221 & & & 14 & 54 & & 289 & A2 & & 29 & 162 & 5 & 8 & 85 & & 289 \\
\hline A3 & 35 & & 58 & 89 & & & 182 & A3 & 40 & 21 & 31 & 4 & 70 & 16 & & 182 \\
\hline A4 & & & & & & 195 & 195 & A & & 78 & & & & & 117 & 195 \\
\hline A5 & 113 & 119 & & 20 & & 39 & 291 & A5 & & 58 & 127 & 48 & 15 & 24 & 19 & 291 \\
\hline A6 & & & 49 & 21 & & & 70 & A6 & 42 & 3 & & & 20 & 5 & & 70 \\
\hline & & & & & & & & & & & & & & & & \\
\hline Total & 414 & 119 & 329 & 159 & 92 & 234 & 1347 & & 226 & 243 & 354 & 67 & 126 & 195 & 136 & 1347 \\
\hline & & & & & & & & & & & & & & & & \\
\hline & & & & & & & & B1 & & 61 & 317 & 8 & & 28 & & 414 \\
\hline & & & & & & & & B2 & & 15 & 37 & 44 & & 23 & & 119 \\
\hline & & & & & & & & B3 & 226 & 53 & & 9 & & 41 & & 329 \\
\hline & & & & & & & & B4 & & 16 & & 6 & 126 & 11 & & 159 \\
\hline & & & & & & & & B5 & & & & & & 92 & & 92 \\
\hline & & & & & & & & B6 & & 98 & & & & & 136 & 234 \\
\hline & & & & & & & & & & & & & & & & \\
\hline & & & & & & & Total & & 226 & 243 & 354 & 67 & 126 & 195 & 136 & 1347 \\
\hline
\end{tabular}

\section{Construction of the Hierarchical Value Map}

The second step of structural analysis is construction of the Hierarchical Value Map or HVM (Reynolds and Gutman, 1998). A conventional HVM shows how consumers link product attributes to product benefits and, ultimately, to personal values, for a specific group of products.

The most important part of this step is the choice of the cut-off level. Due to parsimony, only links between categories (direct or indirect) that are mentioned by a number of respondents exceeding a chosen cut-off level are included in the maps and, from that moment on, are called chains. For a detailed description of the procedures see Reynolds and Gutman (1988). The cut-off level for the HVMs is chosen through a trade-off between a parsimonious and a complete representation of the data. The objective is to make the cut-off level as low as possible to achieve a result approaching desirable idiographic properties and interpretability, yet not yield a map so large and cluttered as to be incomprehensible. Thus the cut-off level determines how many links from the summary implication matrix will be represented in the HVM as chains. The ratio of the links retained to the total number of links is a useful summary measure of the representativeness of the HVM. Gengler and Reynolds (1995) suggest, based on their experience in conducting over 100 laddering studies, that the minimum threshold value of this ratio should never be less than $70 \%$, with an average number typically in the $75 \%$ to $85 \%$ range. To represent any smaller percentage can cause valuable insights to be lost.

With 418 participants, the cut-off level of 16 was selected. Thus, connections had to be made by at least 17 separate participants to be included on the diagram. The ratio $16 / 418=3.8 \%$ is close to the $4 \%-5 \%$ ratio, typically used in other laddering studies. The number of links in the summary implication matrix above the cut-off level is 48 
out of 65, which yields an acceptable measure of the representativeness of the HVM, which we term the Coefficient of Chain Representativeness (CCR), of 74\%. The resulting HVM is presented in Figure 1.

\section{Interpretation of the HVM}

The final step of the structural analysis is the interpretation of the hierarchical value map.

Figure 1 provides a virtually self-explanatory view, on one page, of the motivations of Poles in their purchase of cigarettes. Attributes are represented as clear, white circles; consequences as shaded, gray circles; values as black. The larger the circle, and proportionately the font size, the more ladders include the concept. The wider the arrow, the more ladders exhibited the link between the concepts. This graphical approach for constructing an HVM follows the idea that was first developed by Klenoski et al. (1993) and enhanced further by Gengler et al. (1995).

The chains that are of most importance can be identified easily by looking for the larger circles, connected by the larger arrows. Such an investigation reveals, for example, that some smokers look for mild cigarettes due to their perception that this will result in less health damage, and thereby result in security. Others select cigarettes for their taste, which gives them pleasure and this in turn is associated with the underlying value of hedonism.

Some findings are less obvious. This is particularly true for the less frequently observed connections. For example, the Strong-->Feel Physically Better-->Conformity [Politeness/Obedient] chain may not be intuitively obvious from examination of Figure 1. However, ladders provided in the questionnaires show that those who smoke strong cigarettes feel physically better, which puts them in a better mood and thus makes them less irritable and more likely to be polite.

Figure 1 allows us to quickly identify chains of interest; chains that merit further analysis. We have selected six chains for more rigorous interpretation. This analysis is depicted in Table 6 wherein we identify the six chains, and then we compare the demographic characteristics of those respondents who were represented in the chain significantly more frequently than in the total sample, and the demographic characteristics associated with those represented in the chain significantly less frequently than in the sample.

A cursory scan of the summary results reveals immediate potential for using the study to generate meaningful segments and, potentially, to contribute to public policy recommendations. For example, each of the six chains in Table 6 demonstrates the value of gender as a basis for segmentation. Chains 1 through 4 , in particular, suggest that there are substantial differences between males and females with respect to the individual's motivations for smoking. There are obvious public policy implications for being able to differentiate between males and females as to the underlying reasons for smoking. Some of the results confirm our stereotypical expectations, but others require more interpretation.

\section{Chain \#1: Taste/Aroma->I Feel Pleasure->Hedonism}

Both women and men derive pleasure from smoking, and this consequence of pleasure, in both instances, is linked directly with the value of hedonism. However, women derive pleasure from the taste and aroma of the cigarette whereas men derive pleasure from the strength of the cigarette. That is, Chain \#1 (Taste/Aroma->I Feel Pleasure-->Hedonism) finds women significantly $(\mathrm{p}<0.05)$ more frequently, and men significantly less frequently, represented in the Taste/Aroma-->I Feel Pleasure-->Hedonism chain than in the sample.

High-income respondents are significantly more frequently represented in this chain than in the sample in general, whereas very low-income respondents are somewhat less likely to be represented in the chain. 
Figure 1: Hierarchical value map of Polish smokers

Sample size $n=418 ;$ No. of SIM associations $=65(C C R=74 \%) ;$ No. of ladders $=1,347$

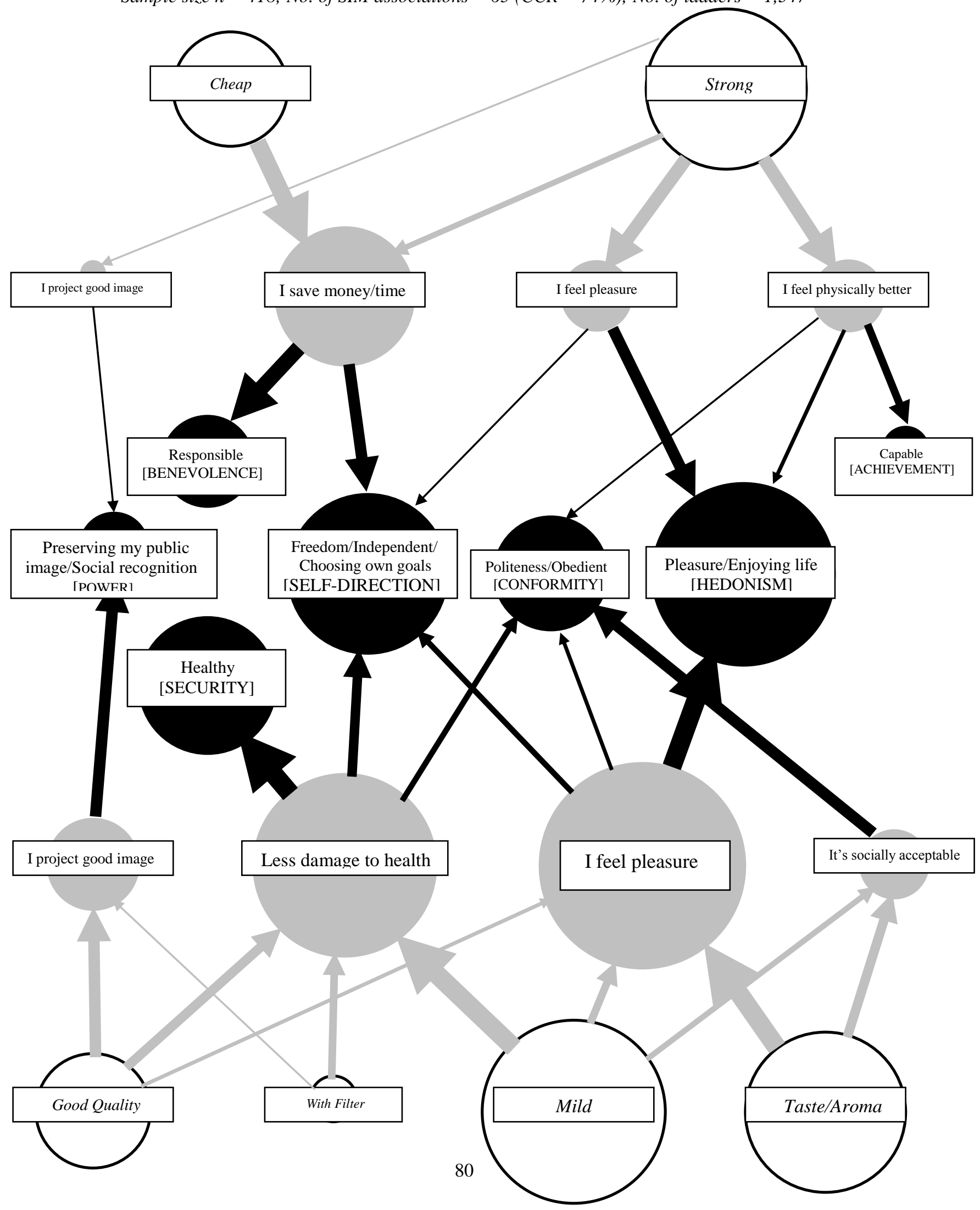


Chain \#2: Mild->Less Damage to Health->Security

There are also gender differences found in Chain \#2. Women are significantly more frequently represented in this chain than in the sample, and men significantly less. The chain of Mild-->Less Damage to Health-->Security has public health implications. Women appear to be more likely to select mild cigarettes for health-related reasons, believing that mild cigarettes are less injurious to health thereby providing a value of security. Women, therefore, would appear to be a legitimate target for policy makers wishing to disabuse the population of the notion that mild cigarettes are "healthy" alternatives.

\section{Chain \#3: Cheap->I Save Money/Time->Benevolence}

Men are represented in Chain \#3 more frequently than the sample, and women less frequently than the sample. It would seem that an appeal based on the money that could be saved from quitting smoking altogether, linked to the value of Benevolence (such as more money to take care of one's family) would be better targeted at males than females.

\section{Chain \#4: Strong->I Feel Pleasure->Hedonism}

Analysis of this chain suggests that men are more frequently, and women less frequently, represented in the chain than in the sample. That is, men are more likely to associate the strength of the cigarette with the pleasure that they derive from smoking it than are women. This becomes more interesting when one compares this chain with Chain \#1. Recall in Chain \#1 that women were more likely to associate Pleasure and Hedonism with the attribute of Taste/Aroma; and men less so. Attempts to eliminate smoking must address the I Feel Pleasure->Hedonism link, but be cognizant of the fact that there are gender differences as to the attributes that are related to the consequence of pleasure. Once again, a somewhat stereotypical assumption that men get more pleasure from the strength of the cigarette than do women, and that women get more pleasure from the taste and aroma of the cigarette, is borne out by these results.

\section{Chain \#5: Cheap->I Save Money/Time->Self-Direction}

This chain becomes more interesting when one contrasts it with Chain \#3. Chain \#5 suggests that there is another value associated with Cheap->Save Money/Time, namely the value of Self-Direction. There is a weaker gender difference here, although in the same direction as for Chain \#3; but this chain is more interesting when one examines education and income. These results suggest that an appeal to Self-Direction would be better targeted towards lower middle-income male smokers with a vocational school education. Whereas the appeal based on Chain \#3 could be towards saving money for helping one's family, the appeal based on Chain \#5 could be saving money to use on other things for oneself.

\section{Chain \#6: Good Quality->I Project Good Image->Power}

The sixth chain provides interesting segmentation possibilities for public policy. Smokers who suggest that good quality is an important attribute in cigarette purchase, and who relate this to their public image, and associate this with an underlying value of power are more often single and between the ages of 22 and 27 . This demographic segment is often the role model for even younger smokers. The powerless seek ways to achieve power, or to give the appearance of possessing power, and this quest for power may be utilized by those responsible for public health to develop strategies to reduce smoking among the young and powerless.

\section{LIMITATIONS OF THE STUDY}

This study has certain limitations that one must consider when examining the relevance of the results. The first of these limitations deals with the generalizability of the sample. A study of the cigarette choice of Poles may in fact be generalizable to only the Polish situation. We have demonstrated that the sample is a reasonable reflection of 
Table 6: Summary of the standard test results

\begin{tabular}{|c|c|c|}
\hline & Represented in the chain significantly & Represented in the chain significance \\
\hline & MORE frequently than sample & LESS frequently than sample \\
\hline CHAIN \#1: A2-B1-V3 & 1. WOMEN* & 1. MEN \\
\hline Taste/Aroma->I Feel Pleasure->Hedonism & 2. HIGH INCOME & Very Low Income** \\
\hline CHAIN \#2: A1-B3-V1 & 1. WOMEN & 1. MEN \\
\hline \multirow[t]{3}{*}{ Mild->Less Damage to Health->Security } & High School & Primary School \\
\hline & 2. [42-47) YRS OLD & 2. VOCATIONAL SCHOOL \\
\hline & 5 Persons in the HSHD & 3 Persons in the HSHD \\
\hline CHAIN \#3: A4-B6-V7 & 1. MEN & 1. WOMEN \\
\hline \multirow[t]{7}{*}{ Cheap->I Save Money/Time->Benevolence } & 2. PRIMARY SCHOOL & College \\
\hline & Vocational School & 2. UNIVERSITY \\
\hline & High School & [27-31) Years Old \\
\hline & 3. 67+ YRS OLD & 2 Persons in the HSHD \\
\hline & 5 Persons in the HSHD & 4. 3 PERSONS IN THE HSHD \\
\hline & 4. 6+ PERSONS IN THE HSHD & 5. UPPER MIDDLE INCOME \\
\hline & 5. LOWER MIDDLE INCOME & 6. VERY HIGH INCOME \\
\hline CHAIN \#4: A5-B1-V3 & 1. MEN & 1. WOMEN \\
\hline \multirow[t]{8}{*}{ Strong->I Feel Pleasure->Hedonism } & Widowed/Separated/Divorced & College \\
\hline & Primary School & University \\
\hline & 2. VOCATIONAL SCHOOL & 2. [37-42) YRS OLD \\
\hline & [27-37) Years Old & Upper Middle Income \\
\hline & [57-62) Years Old & Very High Income \\
\hline & 4 Persons in the HSHD & \\
\hline & Low Income & \\
\hline & Lower Middle Income & \\
\hline CHAIN \#5: A4-B6-V2 & Men & Women \\
\hline \multirow[t]{4}{*}{ Cheap->I Save Money/Time->Self-Direction } & 1. VOCATIONAL SCHOOL & 1. UNIVERSITY \\
\hline & [32-37) Years Old & 3 Persons in the HSHD \\
\hline & $5+$ Persons in the HSHD & 2. UPPER MIDDLE INCOME \\
\hline & 2. LOWER MIDDLE INCOME & \\
\hline CHAIN \#6: A3-B4-V5 & Women & Men \\
\hline \multirow[t]{7}{*}{ Good quality->I Project Good Image>Power } & 1. SINGLE & 1. MARRIED \\
\hline & University & Primary School \\
\hline & [18-22) Years Old & Vocational school \\
\hline & 2. [22-27) YEARS OLD & [52-62) Years Old \\
\hline & 2 Persons in the HSHD & $67+$ Years Old \\
\hline & High Income & $6+$ Persons in the HSHD \\
\hline & Very High Income & Low Income \\
\hline
\end{tabular}

* CATEGORIES WRITTEN WITH BOLD UPPER-CASE LETTERS HAVE p-VALUE BELOW 0.05

** Categories written with lower-case letters have p-value between 0.05 and 0.15

the population of Polish smokers, but extensions to other jurisdictions may be confounded by cultural and political differences. A second, possible limitation was alluded to earlier in the paper (p.4). This potential limitation has to dowith the duality of approaches employed in this study. A third limitation, as is the case with any study of this type, relates to the subjective nature of the coding. However, our choice of cigarettes as the subject of the study, and the use of smokers in the sample, provides a degree of precision not found in several other similar appearing studies that dealt with more abstract concepts as the subject of the laddering. 


\section{FINAL CONCLUSIONS AND DIRECTIONS FOR FUTURE RESEARCH}

The study provides assistance to those responsible for public health to better understand the behavioural underpinnings of tobacco consumption. This understanding brings with it implications for public policy intervention at the consumer behaviour level that go beyond the administrative strictures typically imposed by government agencies. We provide an examination of the chains linking attributes of cigarettes, through the consequences, to the values that underlie the choice of cigarette. It is these chains that are of interest to public policy officials, because each chain provides an opportunity for more precisely targeting public health initiatives.

The study needs to be replicated in other jurisdictions, and perhaps with other product categories. There may be similar public health concerns with the problem of alcohol or drug abuse that would lend itself to this type of analysis.

\section{REFERENCES}

1. Abbott, L. (1955), Quality and Competition: An Essay in Economic Theory, Columbia University Press, New York.

2. Aurifeille, J-M. and P. Valette-Florence (1992a), “A 'Chain-Constrained' Clustering Approach in Means End Analysis: An Empirical Illustration", Proceedings of the $21^{\text {st }}$ Annual Conference of the European Marketing Academy, Aarhus, Denmark, pp. 49-64.

3. Aurifeille, J-M. and P. Valette-Florence (1992b), "A Empirical Investigation of the Predictive Validity of Micro versus Macro Approaches in Consumer Value Research", Proceedings of the $21^{\text {st }}$ Annual Conference of the European Marketing Academy, Aarhus, Denmark, pp. 65-81.

4. Aurifeille, J-M. and P. Valette-Florence (1995), "Determination of the dominant means-end chains: A constrained clustering approach", International Journal of Research in Marketing, 12, pp. 267-278.

5. Bagozzi, Richard P. and P. A. Dabholkar (1994), "Consumer Recycling Goals and Their Effect on Decisions to Recycle: A Means-End Chain Analysis", Psychology and Marketing, 11, pp. 313-340.

6. Bagozzi, Richard P. and P. A. Dabholkar (2000), "Discursive Psychology: An Alternative Conceptual Foundation to Means-End Chain Theory", Psychology and Marketing, 17, pp. 535-586.

7. Bech-Larsen, T., N. A. Nielsen, K. G. Grunert, and E. Sorensen (1997), "Attributes of Low Involvement Products: a Comparison of Five Elicitation Techniques and a Test of Their Nomological Validity", MAPP Working Paper No. 43, The Aarhus School of Business, Aarhus, Denmark.

8. Bech-Larsen, T. and N. A. Nielsen (1999), "A comparison of five elicitation techniques for elicitation of attributes of low involvement products", Journal of Economic Psychology, 20, pp. 315-341.

9. Beck, Ernest (1997), “Ad Bans Abroad Haven’t Snuffed Out Smoking”, Wall Street Journal, June 12.

10. Botchen, Gunther and E. Thelen (1998), "Hard versus Soft Laddering: Implications for Appropriate Use", New Developments and Approaches in Consumer Behavior Research, pp. 322-339, Stuttgart: SchafferPoeschel.

11. Botschen, Gunther and A. Hemetsberger (1998), "Diagnosing Means-End Structures to Determine the Degree of Potential Marketing Program Standarization", Journal of Business Research, 42, pp. 151-159.

12. Celsi, Richard L. and J. C. Olson (1988), "The Role of Involvement in Attention and Comprehension Processes", Journal of Consumer Research, 15, pp. 210-224.

13. Chaloupka, F. J., P. Jha, M. A. Corrao, V. Costa e Silva, H. Ross, C. Czart, and D. Yach (2001) " "The Evidence Base for Reducing Mortality from Smoking in Low and Middle Income Countries", CMH/WHO Working Paper Series, Paper No. WG5: 7.

14. Chapman, S. and B. Fitzgerald (1982), "Brand Preference and Advertising Recall in Adolescent Smokers: Some Implications for Health Promotion", American Journal of Public Health, 82, pp. 491-494.

15. Chassin, L., C. Presson, S. J. Sherman, E. Corty, and R. W. Olshavsky (1981), "Self-images and Cigarette Smoking in Adolescence", Personality and Social Psychology Bulletin, 7, pp. 670-676.

16. Coolen, Henny and J. Hoekstra (2001), "Values as determinants of preferences for housing attributes", Journal of Housing and the Built Environment, 16, pp. 285-306.

17. Deeter-Schmeltz, Dawn R., K. N. Kenndy, and D. J. Goebel (2002), "Understanding sales manager effectiveness: Linking attributes to sales force values”, Industrial Marketing Management, 31, pp. 617-626. 
18. Feunekes, G. I. J. and W. den Hoed (2001), "Quantifying Consumers' Motivational Structures for Food Products. The Association Pattern Technique", in Excellence in International Research, pp. 1-15, ESOMAR, Amsterdam.

19. Gengler, Charles E. and T. J. Reynolds (1995), "Consumer Understanding and Advertising Strategy: Analysis and Strategic Translation of Laddering Data", Journal of Advertising Research, July/August, pp. 19-33.

20. Gengler, Charles E., D. B. Klenosky and M. S. Mulvey (1995), "Improving the graphic representation of means-end results", International Journal of Research in Marketing, 12, pp. 245-256.

21. Grube, Joel W., I. L. Weir, S. Getzlaf, and M. Rokeach (1984), "Own Value System, Value Images, and Cigarette Smoking”, Personality and Social Psychology Bulletin, 10 (2), pp. 306-313.

22. Grunert, Klaus G. and S. C. Grunert (1995), "Measuring subjective meaning structures by the laddering method: Theoretical considerations and methodological problems", International Journal of Research in Marketing, 12, pp. 209-225.

23. Grunert, Klaus G. and H. Juhl (1991), "Values, Environmental Attitudes, and Buying of Organic Foods: Their Relationship in a Sample of Danish Teachers", Proceedings of the Workshop on Values and Lifestyle in Marketing, Brussels: European Institute of Advanced Studies in Management.

24. Gutman, Jonathan (1982), "A Means-End Chain Model Based on Consumer Categorization Process", Journal of Marketing, 46 (2), pp. 60-72.

25. Gutman, Jonathan (1997), "Means-End Chains as Goal Hierarchies", Psychology and Marketing, 14, pp. 545-560.

26. Hamilton, J. L. (1972), "The Demand for Cigarettes: Advertising, the Health Scare, and the Cigarette Advertising Ban", Review of Economic Statistics, 56, pp. 401-411.

27. High, S. Hugh (2000), "Advertising and the Inducement to Smoking", paper presented at the Conference on Individual Choices and Liberty Seminar, University of Quebec, Hull, February.

28. Hofstede, Frenkel T., A. Audenaert, J-B E. M. Steenkamp and M. Wedel (1998), "An investigation into the association pattern technique as a quantitative approach to measuring means-end chains", International Journal of Research in Marketing, 15, pp. 37-50.

29. Hofstede, Frenkel T., J-B E. M. Steenkamp and M. Wedel (1999), "International Market Segmentation Based on Consumer-Product Relations, Journal of Marketing Research, 36, pp. 1-17.

30. Jarvis, Martin J. (1998), "Supermarket Cigarettes: The Brands That Dare Not To Speak Their Name", British Medical Journal, (316), pp. 929-931.

31. Jonas, M. S. and S. C. Beckmann (1998), "Functional Foods: Consumer Perceptions in Denmark and England", MAPP Working Paper No. 55.

32. Kahle, Lynn R. (1983), Social Values and Social Change: Adaptation to Life in America, New York: Praeger.

33. Klenosky, David B., C. E. Gengler and M. S. Mulvey (1993), "Understanding the Factors Influencing Ski Destination Choice: A Means-End Analytic Approach”, Journal of Leisure Research, 25, pp. 362-379.

34. Makatouni, Aikaterini (2002), "What motivates consumers to buy organic food in the UK? Results from a qualitative study", British Food Journal, 104 (3-5), pp. 345-352.

35. Miele, Mara (2000), "Consumer Concerns about Animal Welfare and the Impact on Food Choice", Italian Report on Laddering Interviews, published by University of Pisa

36. Miles, Susan and L. J. Frewer (2001), "Investigating specific concerns about different food hazards", Food Quality and Preference, 12, pp. 47-61.

37. Moschis, G. P. (1989), "Point of View: Cigarette Advertising and Young Smokers", Journal of Advertising Research, 29, pp. 51-60.

38. Mount, Joan and E. Kaciak (1993), "Transforming the Laddering Technique into a Research Tool for Everyday Use", Proceedings of the ASAC 1993 Conference, pp. 205-217.

39. Pechmann, Cornelia and S. J. Knight (2002), "An Experimental Investigation of the Join Effects of Advertising and Peers on Adolescents' Beliefs and Intentions about Cigarette Consumption", Journal of Consumer Research, 29, pp. 5-19.

40. Pierce, John, W. S. Chon, E. A. Gilpin, A. J. Farkas, C. C. Berry (1998), "Tobacco Industry Promotion of Cigarettes and Adolescent Smoking”, Journal of American Medical Association, 279, pp. 511-515. 
41. Pieters, Rik, H. Baumgartner, and H. Stad (1994), "Diagnosing Means-End Structures: The Perception of Word-Pro cessing Software and the Adaptive-Innovative Personality of Managers, in EMAC Proceeding, Vol. 2, Maastricht, pp. 749-762.

42. Pieters, Rik, H. Baumgartner and D. Allen (1995), "A means-end chain approach to consumer goal structures", International Journal of Research in Marketing, 12, pp. 227-244.

43. Pieters, Rik, G. Bottschen, and E. Thelen (1998), "Customer Desire Expectations about Service Employees: An Analysis of Hierarchical Relations", Psychology and Marketing, 15(8), pp. 755-773.

44. Reynolds, Thomas J., C. E. Gengler, and D. Howard (1995), "A means-end analysis of brand persuasion through advertising", International Journal of Research in Marketing, 12, pp. 257-266.

45. Reynols Thomas J. and J. Gutman (1988), "Laddering Theory, Method, Analysis, and Interpretation", Journal of Advertising Research, February/March, pp. 11-31.

46. $\quad$ Rokeach, Milton (1973), The Nature of Human Values, N. Y., The Free Press.

47. Rosenberg, M. J. (1956), "Cognitive Structure and Attitudinal Affect”, Journal of Abnormal and Social Psychology (22), pp. 368-372.

48. Russel, C.G., I. Flight, P. Leppard, J. A. van Lavick van Pabst, J. A. Syrette, and D. N. Cox (2003), “A comparison of paper-and-pencil and computerized methods of 'hard' laddering", Food Quality and Preference, 15, pp. 279-291.

49. Schwartz, Shalom H. (1992), "Universals in the Content and Structure of Values: Theoretical Advances and Empirical Tests in 20 Countries", Advances in Experimental Social Psychology, 25, San Diego, pp. 1-65.

50. Schwartz, Shalom H. (1994), "Are There Universal Aspects in the Structure and Contents of Human Values?" Journal of Social Issues, 50(4), pp. 19-45.

51. Schwartz, Shalom H. and W. Bilsky (1990), "Toward a Theory of Universal Content and Structure of Values: Extensions and Cross-cultural Replications", Journal of Personality and Social Psychology, 58, pp. 878-891.

52. Sheth, J. N., B. I. Newman, and B. L. Gross (1991), "Why We Buy What We Buy: A Theory of Consumption Values", Journal of Business Research, 22, pp. 159-170.

53. Sorensen, Elin, K. G. Grunert, and N. A. Nielsen (1996), "The Impact of Product Experience, Product Involvement and Verbal Processing Style on Consumers' Cognitive Structures with Regard to Fresh Fish", Working Paper No. 42, October, The Aarhus School of Business, Aarhus, Denmark.

54. Stewart, M. J. (1993), "The Effect on Tobacco Consumption of Advertising Bans in OECD Countries", International Journal of Advertising, (12).

55. The World Bank Report (1999): "Curbing the Epidemic - Governments and the Economics of Tobacco Control", The International Bank for Reconstruction and Development, Washington, D.C.

56. Tolman, E. C. (1932), Purposive Behavior in Animals and Men, Century, New York, NY.

57. USDA GAIN Report (2000), "Poland: Tobacco and Products", \#PL0015 (October).

58. Valette-Florence Pierre and B. Rapacchi (1991), "Improvements in Means-End Chain Analysis: Using Graph Theory and Correspondence Analysis", Journal of Advertising Research, February/March, pp. 30-45.

59. Valette-Florence, Pierre (1998), "A Casual Analysis of Means-End Hierarchies in a Cross-Cultural Context: Methodological Refinements", Journal of Business Research, 42, pp. 161-166.

60. Valette-Florence, Pierre, L. Sirieix, K. Grunert, and N. Nielsen (2000), "Means-End Chain Analyses of Fish Consumption in Denmark and France: a Multidimensional Perspective", in L. Khale (ed.) Cross-National Consumer Psychographics, pp. 15-27, New York: Haworth Press.

61. Walker, Beth A. and J. C. Olson (1991), “Means-End Chains: Connecting Products With Self”, Journal of Business Research, (22), pp. 111-118.

62. Wyckham, Robert G. (1997), "Regulating the Marketing of Tobacco Products and Controlling Smoking in Canada", Canadian Journal of Administrative Sciences, 14 (2), pp. 141-165.

63. Young, Shirley and B. Feigin (1975), "Using the Benefit Chain for Improved Strategy Formulation", Journal of Marketing, July, pp. 72-74. 


\section{NOTES}

